\title{
Bacanal narcisista no Louvre: racismo e poder através da adjetivação em um post de Sheila Leirner no jornal Estadão
}

Felipe de Souza Oliveira*

UFSJ

Recebido em: 30/o6/2019

Aceito em: 08/11/2019

RESUMO: Através dos "organizadores globais dos discursos de base ideológica" propostos por Teun A. van Dijk, este trabalho analisa discursivamente um post de autoria de Sheila Leiner em seu blog na seção Cultura do jornal Estadão. A pesquisa toma o uso de adjetivos como pista linguística para compreender o propósito discursivo do post em questão, que se trata de uma crítica negativa a um videoclipe onde a cultura negra é exaltada e se apresenta como capital intelectual. Assim, demonstra a forma na qual a linguagem é empregada na tentativa de manutenção das relações de poder através do(s) discurso(s).

Palavras-chave: Discurso. Racismo. Poder. Adjetivação.

ABSTRACT: Using the "global organizers of ideologically based discourses" proposed by Teun A. van Dijk, this article discursively analyzes a post authored by Sheila Leiner in her blog, hosted at the Culture section of the newspaper Estadão. The research takes the use of adjectives as a linguistic clue to understand the discursive purpose of the mentioned post, which is a negative critique of a music video where black culture is exalted and presented as intellectual capital. Thus, it demonstrates the way in which language is employed in the attempt to maintain power relations through discourse(s).

Keywords: Discourse. Race. Power. Adjectives.

RESUMEN: Por medio de los "organizadores globales de los discursos de base ideológica" propuestos por Teun A. van Dijk, este trabajo analiza discursivamente un post de autoría de Sheila Leiner en su blog en la sección Cultura del periódico Estadão. La investigación toma el uso de adjetivos como pista lingüística para comprender el propósito discursivo del post en cuestión, que se trata de una crítica negativa a un videoclip donde la cultura negra es exaltada y presentada como capital intelectual. Así, demuestra la forma en que el lenguaje se emplea en el intento de mantener las relaciones de poder a través del discurso (s).

Palabras clave: Discurso. Racismo. Poder. Adjetivos. 


\section{Cultura, discurso, racismo e poder}

Falar sobre racismo é um assunto delicado por diversos motivos. Em parte, pela dificuldade em defini-lo com precisão, e também pela intensidade em que este é negado em nossa sociedade (VAN DIJK, 20o8a, p. 155). É importante entender, porém, que ele faz parte da estrutura social, e isso traz implicações profundas nas realidades em que vivemos.

Para entendermos melhor essa estrutura racista numa formação sociológica, temos que pensar na constituição da sociedade em si. Giddens (2003) diz que a sociedade é constituída a partir de estruturas, que são “conjuntos de regras e recursos, implicados na articulação institucional de sistemas sociais” (GIDDENS, 2003, p. 442). Ou seja, a sociedade se organiza através de regras gerais, que dentro do espaço e tempo podem ser mais abstratas ou formalizadas, e a aplicação dessas regras contribui para a reprodução da própria sociedade e seus sistemas. Essa discussão passa também pelos conceitos de cultura, pois cultura e sociedade estão intrinsicamente ligadas, uma vez que a:

Cultura é uma dimensão do processo social, da vida de uma sociedade. Não diz respeito apenas a um conjunto de práticas e concepções, como por exemplo se poderia dizer da arte. Não é apenas uma parte da vida social como por exemplo poderia se falar da religião. Não se pode dizer que cultura seja algo independente da vida social, algo que nada tenha a ver com a realidade onde existe. Entendida dessa forma, cultura diz respeito a todos os aspectos da vida social, e não se pode dizer que ela exista em alguns contextos e não em outros (SANTOS, J., 1983, p. 44-45).

Mais do que isso, temos que pensar também no "quanto as concepções de cultura e o próprio conteúdo da cultura estiveram sempre associados às relações entre as classes sociais" (SANTOS, J., 1983, p. 58). Falar sobre sociedade é indiretamente falar sobre a diferença de classes, e nesse sentido, podemos considerar alguns apontamentos sobre poder, acesso e a forma que eles estão presentes na constituição da sociedade.

Tylor (2005) diz que "um primeiro passo no estudo da civilização é dissecá-la em detalhes e, em seguida, classificá-los em seus grupos apropriados” (TYLOR, 2005, p. 76). Porém, estudos deste tipo apresentam um problema ao tentar hierarquizar as sociedades humanas como parte de uma escala evolutiva, fazendo com que as diferenças sociais 
sejam encaradas como estágios diferentes da evolução humana. Isso cria uma ideia de que certos povos se encontram em situação de barbárie e selvageria, enquanto outras comunidades já teriam passado por todas as etapas evolutivas e se tornado “civilizadas", sendo a Europa ocidental tida como o ápice dessa escala evolutiva civilizatória. Essa visão acaba servindo ao "propósito de legitimar o processo (...) de expansão e consolidação do domínio dos principais países capitalistas sobre os povos do mundo" (SANTOS, J., 1983, p. 14). É importante pensar também, que

\begin{abstract}
a avaliação de cada cultura e do conjunto das culturas existentes varia de acordo com a cultura particular da qual se efetue a observação e análise; isso diria respeito a qualquer caso e não só ao da visão europeia de evolução social única dos grupos humanos (...). Verifica-se assim que a observação de culturas alheias se faz segundo pontos de vista definidos pela cultura do observador, que os critérios que se usa para classificar uma cultura são também culturais. (SANTOS, J., 1983, p. 16).
\end{abstract}

Ou seja, podemos perceber como a sociedade foi e é estruturada com base na dominação entre os povos, e essa dominação gera diferenças nas relações de poder entre eles. Van Dijk, (2008a) sumariza que o "poder social é definido em torno do controle exercido por um grupo ou organização (ou seus integrantes) sobre as ações e/ou as mentes de (membros de) um outro grupo" (VAN DIJK, 2008a, p. 88). Dessa forma, os grupos dominados têm acesso limitado a recursos sociais como empregos e bens materiais, além de geralmente terem seu acesso ao discurso e à comunicação dificultados (VAN DIJK, 2008a, p. 88). Assim:

a existência das classes dominadas denuncia as desigualdades sociais e a necessidade de superá-las, sua cultura pode ser vista como tendo um conteúdo transformador. Da mesma forma, como a cultura erudita é desde sempre associada com as classes dominantes, sua expansão pode ser vista como uma expansão colonizadora (SANTOS, J., 1983, p. 55-56).

Dessa forma, o conhecimento das classes dominantes é tido como superior, erudito, enquanto a cultura das classes dominadas é caracterizada como inferior, popular. Essas duas dimensões são sempre pensadas em relação uma com a outra, enfatizando suas diferenças apesar de serem contemporâneas. Isso por vezes traz um caráter de resistência para a chamada cultura popular, em relação à dominação que 
inviabiliza outras formas de conhecimento (SANTOS, J., 1983, p. 56; RIBEIRO, 2017, p. 24-25).

Assim, partindo-se do princípio de que "a existência do poder pressupõe estruturas de dominação por meio das quais o poder que 'flui suavemente' em processos de reprodução social (e é, por assim dizer, 'invisível') opera” (GIDDENS, 2003, p. 303), podemos começar a falar sobre racismo.

Van Dijk (2008a, p. 134-135) entende o racismo como um desses sistemas sociais de dominação, composto por um subsistema social e um cognitivo. O subsistema social atua nos níveis micro e macro, o primeiro representado pelas práticas sociais de discriminação em planos locais, e o segundo por atos e relações de abuso de poder praticados num contexto mais amplo, por grupos, organizações e instituições dominantes. Já o subsistema cognitivo diz respeito a preconceitos e ideologias racistas presentes nas representações mentais compartilhadas socialmente.

Dessa forma, as manifestações do racismo no cotidiano são expressões de algo mais profundo que integra a organização da sociedade. São, portanto, uma “manifestação normal da sociedade, e não um fenômeno patológico” (ALMEIDA, 2018, p. 15). Em outras palavras, dizendo "de modo mais direto: as instituições são racistas porque a sociedade é racista" (ALMEIDA, 2018, p. 36).

\section{Discurso e poder na mídia}

Há algumas considerações importantes a se fazer em relação ao papel da mídia nas discussões sobre discurso, racismo e poder.

Os veículos de comunicação no Brasil (...) reproduzem estereótipos solidamente arraigados na mentalidade nacional. A população negra e afrodescendente é impedida de se ver refletida de forma positiva no espelho da mídia e, quando aparece, sua imagem ganha contornos construídos pelo imaginário do preconceito racial, reforçando imagens distorcidas e estereotipadas de nossa realidade (SANTOS, R.,2003, p. 203).

Os meios de comunicação são poderosos e fazem parte da paisagem social moderna, e não apenas são responsáveis por disseminar as informações ao grande público, mas também de difundir maneiras de se comportar, em busca de uma 
homogeneização da sociedade e um amaciamento dos conflitos sociais (SANTOS, J., 1983, p. 69).

Os jornalistas, nesse sentido, "aprendem como retratar o poder dos outros e, ao mesmo tempo, aprendem como contribuir para o poder de sua própria organização" (VAN DIJK, 2008a, p. 74). São, portanto, também poderosos, pela posição social que ocupam e pelo poder que têm em conferir valor jornalístico aos tópicos escolhidos, além de influenciar e persuadir as mentes dos leitores, sendo parte constituinte do poder de uma organização (VAN DIJK, 2008a, p. 21, 104). O jornalista está, então, dentro de uma organização que busca perpetuar as estruturas de poder, mas isso não o exime também de sua própria posição, onde constrói um espaço no qual ele se encontra em posição de ser o árbitro (BOURDIEU, 1989, p. 55).

\section{O material de análise}

O material de análise é uma postagem de Sheila Leirner em seu $b l o g$, localizado na seção Cultura do site do jornal O Estado de São Paulo, conhecido como Estadão. Leirner é "jornalista, crítica de arte, escritora, memorialista, gastrônoma, escreve desde 1975 para o jornal 'O Estado' e foi curadora de duas bienais. Mora e trabalha em Paris, com o coração em São Paulo"1 . Essa descrição disponível no site do jornal indica a criação de um ethos, ou seja, a construção particular de uma identidade social que se dá através do seu comportamento em geral, e não somente verbal (FAIRCLOUGH, 2001, p. 216-217). Ao fazer essa descrição, o jornal pretende comprovar a credibilidade da autora e situá-la numa posição onde possa ser uma locutora confiável. O ethos discursivo se caracteriza não somente pela construção da autoridade da autora, mas também pela competência do próprio jornal, estabelecendo uma relação entre essas duas partes que ajuda na afirmação para o leitor de que ambas são fontes seguras e legítimas. Não somente os sujeitos destinatários dos jornais são diversos, mas o jornal em si também o é, tendo em vista que:

\footnotetext{
${ }^{1}$ Disponível em <https://cultura.estadao.com.br/blogs/sheila-leirner/>. Acesso em 5 out. 2018. Revista Investigaçũes, Recife, v. 32, n. 2, p. 507 - 521, Dezembro/2019
} 
Todo jornal é resultado da articulação de diferentes instâncias enunciativas (i) pela diversidade temática indicada pelos diferentes cadernos/colunas; (ii) pelos vários sujeitos na instância de produção, ora indicados materialmente, ora diluídos sob o nome do próprio jornal (uma empresa que, do ponto de vista enunciativo, constitui-se como sujeito); e (iii) pelos múltiplos sujeitos na instância de recepção (LYSARDO-DIAS, 2017, p. 220).

Apesar disso, dentro de toda pluralidade possível e esperada de receptores, todo discurso é construído com uma projeção idealizada dos seus sujeitos receptores. O perfil do leitor do jornal O Estado de São Paulo caracteriza-se por ser em sua maioria homens, entre 25 e 44 anos, das classes A e $\mathrm{B}^{2}$. Assim, os conteúdos produzidos e disseminados no e pelo jornal são pautados sob a ideia desse leitor considerado padrão.

A postagem se trata de uma crítica ao videoclipe lançado pela dupla The Carters, formado pelos cantores e compositores estadunidenses Jay-Z e Beyoncé. O videoclipe foi lançado no dia 16 de junho de 2018, na plataforma YouTube ${ }^{3}$, sem nenhum anúncio prévio. Ambientado no Louvre, em Paris, traz o casal e outros dançarinos negros se exibindo nas dependências do museu, dividindo o espaço com pinturas e esculturas consagradas. O clipe foi recebido como um manifesto pela negritude, um acerto de contas que reivindica o lugar ao sol do casal entre as elites culturais, já que são vistos apenas como elite financeira (MARTÍ, 2018). A escolha do Louvre é bastante representativa nessa reivindicação de poder, já que o museu:

\footnotetext{
é talvez o maior símbolo de poder, cuja história é permeada de saque colonial - como das obras do setor egípcio, onde eles aparecem algumas vezes -, frequentado, como são os museus de modo geral, por pessoas brancas, com obras de artistas, em sua grande maioria, brancos e também maioria de personagens brancos pintados nas telas (MENEZES, 2018).
}

Ao levar o corpo fora da história e da norma ao centro do palácio (MARTÍ, 2018), há uma positivação da imagem do negro, que aparece ocupando os espaços que lhe são institucionalmente negados. Isso é importante pois:

essas imagens vão ressignificar o imaginário que será abalado e simultaneamente reconstruído. O cinema, o teatro, a televisão, a moda, a música, a dança e todas as expressões artísticas serão ferramentas importantes para que isso seja colocado em prática e justamente por isso que é um dos

2 Disponível em <http://publicidade.estadao.com.br/estadao/estadao-dados-de-mercado/>. Acesso em 05 out. 2018.

${ }^{3}$ Disponível em <https://www.youtube.com/watch?v=kbMqWXnpXcA>. Acesso em 5 out. 2018.

Revista Investigações, Recife, v. 32, n. 2, p. 507 - 521, Dezembro/2019 
campos mais perversos de lidar com o racismo atuante. Nesses lugares de trabalho imagético somos sistematicamente excluídos, dando a ideia de que não existimos enquanto seres artísticos e, portanto, portadores de estética desejável ou ainda, somos colocados em número desproporcional em relação aos brancos e em lugares de pouca visibilidade (BERTH, 2018, p. 103).

Tendo isso em vista, ao mesmo tempo em que pode ser visto então como uma expressão de valorização da cultura negra, atos desse tipo também recebem muitas críticas, principalmente das camadas da sociedade que tentam deslegitimar e ignorar esses movimentos.

O post em questão, criado no dia 23 de junho de 2018 e intitulado "Bacanal narcisista no Louvre"4, é uma crítica ao videoclipe produzido pelo duo denominado The Carters. Considero importante apontar que o blog da jornalista não costuma se dedicar a análises de videoclipes e nem a produtos da considerada cultura de massa. Dos quatorze posts realizados no ano de 2018 , anteriormente ao utilizado aqui como corpus de análise, nenhum fazia referências a obras populares. Porém, pelo fato de o videoclipe ser ambientado no Museu do Louvre, em Paris, abriu-se um espaço de diálogo entre a obra e o blog da autora. Ao trazer um produto que não necessariamente faz parte do seu habitat natural (e nem do seu leitor idealizado), cria-se automaticamente um conflito que ficará explícito ao se falar desse produto dentro do seu próprio discurso.

\section{Adjetivação como categoria de análise}

Van Dijk (2008a, p. 135-136) não compreende o discurso como uma forma genérica, que denota uma classe de gêneros do discurso ou coleções de fala e/ou escrita, como uma ideologia, uma filosofia ou um sistema social. Para ele, o termo discurso é usado "para significar somente um evento comunicativo específico, em geral, e uma forma oral ou escrita de interação verbal ou uso da língua, em particular" (VAN DIJK, 2008a, p. 135).

Van Dijk (2008b, p. 18) elenca de maneira simplificada quatro organizadores globais dos discursos de base ideológica, ao qual o discurso racista se enquadra. Esses artifícios resumem as propriedades discursivas e podem ser aplicadas a todos os níveis e

4 Disponível em <https://cultura.estadao.com.br/blogs/sheila-leirner/bacanal-narcisista-no-louvre/>. Acesso em 23 jun. 2018.

Revista Investigações, Recife, v. 32, n. 2, p. 507 - 521, Dezembro/2019 
dimensões do discurso. São eles: (a) enfatizam os aspectos positivos do Nós, do grupo de dentro; (b) enfatizam os aspectos negativos do Eles, do grupo de fora; (c) não enfatizam os aspectos positivos do Eles; (d) não enfatizam os aspectos negativos do Nós.

Uma das formas de se perceber essas estratégias é através do exame do emprego de adjetivos, uma vez que “o processo de adjetivação é extremamente importante para a análise textual pelo potencial restritivo e particularizador que os adjetivos impõem a outros itens previamente escolhidos" (CARMO, 2006, p. 115). Assim, podemos perceber alguns desses aspectos no texto, conforme os excertos a seguir:

(1) (...) o Louvre certamente é mais distinto.

(2) Os dois se contorcem diante de quadros que não olham, enquanto outros personagens posam, igualmente de costas para as obras mais importantes do museu Vênus de Milo, Vitória de Samotrácia, Coroação de Napoleão, Balsa da Medusa, Gioconda.

Situando-se como parte integrante do Nós, a autora emprega adjetivos para caracterizar o Louvre e suas obras positivamente (a), como vemos em (1) e (2). Essa caracterização também evidencia o distanciamento entre o lugar social ocupado pelo Nós e o lugar do Eles.

(3) O patriota Peruggia fez melhor quando roubou a Mona Lisa do museu em 1911.

As escolhas lexicais em (3) revelam-se como a estratégia de "não enfatizar os aspectos negativos do Nós" (d). Primeiramente, o ladrão italiano de quadros é referenciado como "patriota", ao passo que seu ato de ter roubado a Mona Lisa é, na opinião da autora, considerado como "melhor" que a expressão artística do casal de músicos. Assim, ela atenua a gravidade do fato, ou seja, não enfatiza seu aspecto negativo, protegendo o autor do delito e ainda o colocando como superior a Beyoncé e Jay-Z. Por outro lado, temos:

(4) Bacanal narcisista no Louvre.

(5) O mau gosto atroz impera. 
(6) Não, não estamos sonhando, não é pesadelo, apenas um mau momento brega (...).

(7) O clipe (...) é da mesma arrogância sem par.

(8) No entanto, mesmo em instituição cultural, não são muito elegantes o escárnio, cinismo, oportunismo e atrevimento destes novos filisteus.

(9) Os selfies deles, com vestimentas perfeitamente adaptadas a uma visita de museu, de costas para a Mona Lisa, não podem ser mais cafonas.

(10) E sem dizer também que essa música (letra inclusive) de Beyoncé e Jay-Z é boa para "boi dormir".

Nos trechos acima, vemos a estratégia de (b) sendo aplicada para apresentar os artistas do videoclipe de forma negativa. No título da postagem do blog (4), a adjetivação é derivada de Baco e Narciso, duas figuras mitológicas que remetem à desordem e à vaidade, respectivamente. A ambientação, "no Louvre”, serve como uma contraposição, como se as ações praticadas - o bacanal narcisista - não devessem acontecer ali, pois são brega[s] (6), de uma arrogância sem par (7), não muito elegantes (8) cafonas (9) e, conforme mostrado em (1), o museu é um local mais consagrado. Em (10), ao falar sobre a letra da música, a jornalista diz que é "boa para 'boi dormir”, ou seja, para enganar (BORBA, 2005, p. 189).

As asserções são mais gerais, não direcionadas diretamente aos artistas, mas sim às suas atitudes, com exceção do uso de "novos filisteus" em (7), onde ela se dirige a eles com o sentido de enquadrá-los como vulgares de espírito (BORBA, 2005, p. 617). Comentários com um viés mais pessoal e menos institucionalizado também podem ser vistos em:

(11) Que bom que a Mona Lisa, segundo o insolente rapaz, vai “durar tanto”...

(12) Mas se os pretensiosos Jay-Z e Beyoncé podem alugar um estádio inteiro de rúgbi, não surpreende que possuam meios de se oferecer um Louvre voraz de dinheiro e publicidade.

Há ainda a presença de (a) e (b) simultaneamente, aumentando ainda mais o conflito Nós x Eles: 
(13) O clipe, esta pequena vingança política afro-americana sobre a grande cultura dos homens brancos, é da mesma arrogância sem par.

Assim, temos em (13) as dualidades pequena/grande e afro-americana/brancos. Aqui, o posicionamento se torna claro no sentido de colocar os afro-americanos numa posição inferior, ao mesmo tempo em que enaltece a cultura dos brancos europeus.

É importante notar que no dia seguinte à publicação original, a autora editou o texto e suprimiu o trecho "dos brancos", criando um novo enunciado:

(14) O clipe, esta pequena vingança política afro-americana sobre a grande cultura, é da mesma arrogância sem par.

Figura 1 - Captura de tela de um trecho da postagem no dia 23/o6/2018

$$
\begin{aligned}
& \text { O clipe, esta pequena vingança política } \\
& \text { afro-americana sobre a grande cultura } \\
& \text { dos homens brancos, é da mesma } \\
& \text { arrogância sem par. O patriota Peruggia }
\end{aligned}
$$

Fonte: Captura de tela elabora pelo autor, obtida no site do jornal Estadão. Disponível em $<$ https://cultura.estadao.com.br/blogs/sheila-leirner/bacanal-narcisista-no-louvre/>. Acesso em 23 jun. 2018.

Figura 2 - Captura de tela do mesmo trecho editado da postagem no dia 24/o6/2018

$$
\begin{aligned}
& \text { O clipe, esta pequena vingança política } \\
& \text { afro-americana sobre a grande cultura, } \\
& \text { é da mesma arrogância sem par. o }
\end{aligned}
$$

Fonte: Captura de tela elabora pelo autor, obtida no site do jornal Estadão. Disponível em $<$ https://cultura.estadao.com.br/blogs/sheila-leirner/bacanal-narcisista-no-louvre/>. Acesso em 24 jun. 2018.

Essa reformulação tornou-se menos direta, atenuando a mensagem original. Sobre esse tipo de prática, Van Dijk diz que:

De modo interessante, descobrimos que exatamente o discurso mais racista tende a incluir ressalvas e outras formas de negação. Isso sugere que os usuários Revista Investigações, Recife, v. 32, n. 2, p. 507 - 521, Dezembro/2019 
da língua que proferem coisas negativas sobre as minorias estão bem conscientes do fato de que podem ser interpretados como infratores da norma social de tolerância e aceitação (VAN DIJK, 2008a, p. 158).

Ainda sobre a congruência das estratégias (a) e (b) num mesmo trecho, temos:

(15) (...) eis o preço que a velha Europa deve pagar pela última e verdadeira expressão da América vulgar, ignorante e submissa, de Obama a Trump!

Em (15), a autora estabelece uma relação conflituosa entre o continente europeu e os Estados Unidos, generalizados por ela como apenas "América”. "Velha” pode ser posta como contrário à "última”, observando-se que nesse caso "velha” não tem caráter negativo. Pelo contrário, refere-se à ideia de países consagrados e poderosos, as potências citadas por Marx e Engels como parte de uma união para conjurar o espectro do comunismo que rondava a Europa. (MARX; ENGELS, 1998, p. 39). No campo cultural, essa consagração se apresenta como superioridade artística e intelectual, sendo então tudo que é novo, inferior. Daí a "última” expressão norte-americana ser tida como "vulgar, ignorante e submissa" em comparação com a cultura europeia.

Abaixo, na Tabela 1, podemos ter uma visualização resumida da estratégia discursiva empregada no post e aqui analisada, através do agrupamento das adjetivações conforme os quatro organizadores globais dos discursos de base ideológica. Primeiramente, temos a estratégia de enfatizar os aspectos positivos do Nós (a), onde a jornalista enaltece a arte europeia. Na estratégia de enfatizar os aspectos negativos do Eles, observamos os adjetivos usados pra descrever os artistas e o clipe, numa tentativa de desqualificação dos mesmos. Vale ressaltar que a estratégia de não enfatizar os aspectos positivos do Eles (c) não aparece no material de análise, tendo em vista que a autora não utiliza adjetivos para positivar o clipe ou os artistas relacionados a ele. Por fim, entendemos a estratégia de não enfatizar os aspectos negativos do Nós (d) como a tentativa de subversão de atitudes negativas através da adjetivação positiva escolhida pela autora ao descrever tais atos.

Tabela 1 - Agrupamento das adjetivações conforme os organizadores globais dos discursos de base ideológica 


\begin{tabular}{|c|c|c|}
\hline $\begin{array}{l}\text { a) Enfatizam os aspectos positivos } \\
\text { do Nós }\end{array}$ & \multicolumn{2}{|c|}{ b) Enfatizam os aspectos negativos do Eles } \\
\hline $\begin{array}{l}\text { mais distintos } \\
\text { mais importantes } \\
\text { grande } \\
\text { brancos } \\
\text { velha }\end{array}$ & $\begin{array}{l}\text { bacanal } \\
\text { narcisista } \\
\text { mau gosto } \\
\text { atroz } \\
\text { mau momento } \\
\text { brega } \\
\text { arrogância sem par } \\
\text { não muito elegantes } \\
\text { novos filisteus } \\
\text { cafonas }\end{array}$ & $\begin{array}{l}\text { boas para "boi dormir" } \\
\text { insolentes } \\
\text { pretensiosos } \\
\text { pequena } \\
\text { afro-americana } \\
\text { última } \\
\text { verdadeira } \\
\text { vulgar } \\
\text { ignorante } \\
\text { submissa }\end{array}$ \\
\hline $\begin{array}{l}\text { c) Não enfatizam os aspectos } \\
\text { positivos do Eles }\end{array}$ & \multicolumn{2}{|c|}{$\begin{array}{l}\text { d) Não enfatizam os aspectos negativos do } \\
\text { Nós }\end{array}$} \\
\hline- & $\begin{array}{l}\text { patriota } \\
\text { melhor }\end{array}$ & \\
\hline
\end{tabular}

Fonte: Elaborada pelo autor

\section{Considerações finais}

Considerando as proposições de Van Dijk (2008a, p. 155) de que "os preconceitos étnicos e raciais são predominantemente adquiridos e partilhados dentro do grupo branco dominante, através da conversação cotidiana e da escrita e da fala institucional”, podemos perceber que a linguagem é uma das formas de manutenção de poder (RIBEIRO, 2017, p. 26).

A análise aqui conduzida empenhou-se em tentar evidenciar algumas formas e estratégias utilizadas na tentativa dessa manutenção. Através da postagem no blog, que serviu como uma resposta ao videoclipe criado pelo casal Jay-Z e Beyoncé, podemos 
perceber como o discurso e a linguagem são usados com o intuito de tentar combater ideias que questionem o status quo da estruturação da sociedade, que favorece os grupos hegemônicos.

Vale lembrar que a sociedade nunca se encontra estática ou completa, e sua constante evolução é uma das suas características constitutivas. O que podemos perceber é a forma em que as mudanças não são bem vistas pelos grupos dominantes, que tentam utilizar do seu acesso privilegiado aos recursos sociais para continuar perpetuando a sua dominação.

Assim, ao criticar o videoclipe - que é ele mesmo também uma crítica - podemos perceber a utilização de estratégias padronizadas e amplamente aplicadas pelos grupos dominantes na nossa sociedade. Através de uma análise da adjetivação na matéria estudada, podemos encontrar características de uma dualidade comumente posta como Nós x Eles.

As escolhas lexicais são características que, ao serem analisadas, acabam por demonstrar os resultados previstos pelos estudiosos do discurso, mostrando como as relações de poder se estabelecem na nossa sociedade e como a linguagem é usada na tentativa de manutenção dessas relações.

\section{Referências}

ALMEIDA, Silvio. O que é racismo estrutural? Belo Horizonte: Letramento, 2018.

BERTH, Joice. O que é empoderamento? Belo Horizonte: Letramento, 2018.

BORBA, Francisco da Silva. Dicionário Unesp do português contemporâneo. São Paulo: Unesp, 2005 .

BOURDIEU, Pierre. O poder simbólico. Rio de Janeiro: Bertrand Brasil, 1989.

CARMO, Cláudio Márcio do. Do texto ao ideológico: uma análise de alguns elementos textuais do discurso da Igreja Universal do Reino de Deus na mídia televisiva. Tópicos de Linguagem: Revista de estudos de lingüística e literatura, Barbacena: s.n, v.1, n.2, p. 111-132, nov. 2006.

FAIRCLOUGH, Norman. Discurso e mudança social. Brasília: UnB, 2001.

GIDDENS, Anthony. A constituição da sociedade. São Paulo: Martins Fontes, 2003.

Revista Investigações, Recife, v. 32, n. 2, p. 507 - 521, Dezembro/2019 
LYSARDO-DIAS, Dylia. Configuração enunciativa de perfis biográficos. In: ASSUNÇÃO, Antônio Luiz; BIAVATI, Nádia Dolores Fernandes; SPERANDIO, Natália Elvira (Org.). Interfaces do linguístico: enunciação e práticas discursivas. Campinas: Pontes Editores, 2017.

MARTÍ, Silas. Jay-Z e Beyoncé se afirmam não só entre elites financeiras, mas também culturais. Folha de São Paulo. Disponível em: <https://www1.folha.uol.com.br/ilustrada/2018/o6/jay-z-e-beyonce-se-afirmam-nao soentre-elites-financeiras-mas-tambem-culturais.shtml> Acesso em 14 de novembro de 2018.

MARX, Karl; ENGELS, Friedrich. Manifesto comunista. São Paulo: Boitempo, 1998.

MENEZES, Hélio. In: LIMA, Juliana Domingos de. Como Beyoncé e Jay-Z dialogam com a história da arte no clipe de 'Apeshit'. Nexo Jornal. Disponível em: <https://www.nexojornal.com.br/expresso/2018/o6/18/Como-Beyonc\%C3\%A9-e-Jay-Zdialogam-com-a-hist $\% \mathrm{C}_{3} \% \mathrm{~B}_{3}$ ria-da-arte-no-clipe-de-

\%E2\%80\%98Apeshit\%E2\%80\%99> Acesso em 14 de novembro de 2018.

RIBEIRO, Djamila. O que é lugar de fala? Belo Horizonte: Letramento, 2017.

SANTOS, José Luiz dos. O que é cultura. São Paulo: Brasiliense, 1983, paginação irregular.

SANTOS, Regina dos. Reflexões sobre o racismo no contexto da mídia e das concessões dos meios de comunicação no Brasil. In: Racismos contemporâneos. Rio de Janeiro: Takano, 2003.

TYLOR, Edward Burnett. A ciência da cultura. In: Evolucionismo cultural: textos de Morgan, Tylor e Frazer. Rio de janeiro: Jorge Zahar, 2005.

VAN DIJK, Teun A. Discurso e poder. São Paulo: Contexto, 20o8a. . Racismo e discurso na América Latina. São Paulo: Contexto, 20o8b.

ANEXO 1 - Íntegra do texto publicado

\section{Bacanal narcisista no Louvre}

'Apeshit' (fezes de macaco), o título do novo clipe de Jay-z e Beyoncé já diz tudo: a partir do hábito de macacos raivosos arremessarem suas próprias fezes no que odeiam, este nome significa 'a raiva que produz nos humanos um comportamento parecido com o do macaco enfurecido.'

Pois é exatamente o que o novo videoclipe do casal parece fazer com a arte e a instituição que lhe serve de cenário. Os dois se contorcem diante de quadros que não olham, enquanto outros 
personagens posam, igualmente de costas para as obras mais importantes do museu: Vênus de Milo, Vitória de Samotrácia, Coroação de Napoleão, Balsa da Medusa, Gioconda. O mau gosto atroz impera.

Não, não estamos sonhando, não é pesadelo, apenas um mau momento brega que felizmente não vai durar como a Mona Lisa, ao contrário do que disse Jay-Z. Sim, porque na entrevista que o rapper deu à Times Magazine, ele pergunta: "É melhor ser uma tendência ou ser Ralph Lauren? Melhor ser uma tendência ou ser eterno?" E afirma: "Serei como a Mona Lisa, cara! Me identifico com a verdade! Vou ser cool em 40 anos." Que bom que a Mona Lisa, segundo o insolente rapaz, vai "durar tanto"...

O clipe, esta pequena vingança política afro-americana sobre a grande cultura, é da mesma arrogância sem par. O patriota Peruggia fez melhor quando roubou a Mona Lisa do museu em 1911. Mas se os pretensiosos Jay-Z e Beyoncé podem alugar um estádio inteiro de rúgbi, não surpreende que possuam meios de se oferecer um Louvre voraz de dinheiro e publicidade.

Depois de Niggas in Paris (2011) de Jay-Z e Kanye West - do seu álbum Watch the Throne - onde eles contam as seis noites no hotel de luxo Le Meurice no qual se esbaldam com modelos, álcool e o resto, consumindo 144 mil euros, e citando pelo menos 8 marcas de luxo (por contrato), o Louvre certamente é mais distinto.

No entanto, mesmo em instituição cultural, não são muito elegantes o escárnio, cinismo, oportunismo e atrevimento destes novos filisteus. Os selfies deles, com vestimentas perfeitamente adaptadas a uma visita de museu, de costas para a Mona Lisa, não podem ser mais cafonas. Ego-retratos capazes de fazer Leonardo se revirar em seu túmulo...

Isso, sem dizer que o significado de "Apeshit", título desse videoclipe, é bastante ambíguo. Dentro do contexto, pode ser considerado racista. E sem dizer também que essa música (letra inclusive) de Beyoncé e Jay-Z é boa para "boi dormir". Quem quiser curtir clipe viral, sem ficar com sono, é muito melhor assistir ao excelente "Childish Gambino - This Is America" (vídeo abaixo).

Até a próxima, que agora é hoje e eis o preço que a velha Europa deve pagar pela última e verdadeira expressão da América vulgar, ignorante e submissa, de Obama a Trump!

\footnotetext{
${ }^{*}$ Mestrando do Programa de Pós-Graduação em Letras: Teoria Literária e Crítica da Cultura, área de concentração Discurso e Representação Social.
} 